\title{
ADOLESCENTES AUTORES DE ATOS INFRACIONAIS: DIFICULDADES DE ACESSO E PERMANÊNCIA NA ESCOLA
}

\author{
ADOLESCENTES AUTORES DE INFRACCIONES: \\ DIFICULTADES DE ACCESO Y PERMANENCIA EN LA ESCUELA \\ TEENAGERS RESPONSIBLE FOR INFRACTIONS: \\ DIFFICULTIES IN ACCESSING AND STAYING IN SCHOOL
} Priscila Carla Cardoso ${ }^{1}$ e Débora Cristina Fonseca ${ }^{1}$

${ }^{1}$ Universidade Estadual Paulista “Júlio de Mesquita Filho” - Unesp Rio Claro/SP, Brasil

\begin{abstract}
RESUMO: Este artigo discute parte de uma pesquisa que teve como objetivo compreender a construção da identidade de adolescentes autores de atos infracionais durante suas trajetórias escolares. O enfoque deste artigo trata das dificuldades enfrentadas por esses alunos em acessar e permanecer no sistema educacional e as implicações na constituição das suas identidades. A pesquisa se utilizou de registros dos Livros de Ocorrência Escolares (LOE), de processos judiciais e entrevistas com os adolescentes. A análise foi feita a partir de núcleos de significação apreendidos nos discursos dos adolescentes, em conjunto com a análise documental. Os dados demonstraram que a escola é um lugar, para a maioria desses adolescentes, de reposição de identidade estigmatizada, o que dificulta o acesso e a permanência nesse ambiente. Portanto, o estudo sugere uma urgente discussão no âmbito das políticas públicas de educação que visem o acesso e a permanência desses adolescentes na escola.

PALAVRAS-CHAVE: Adolescentes; Educação; Ato Infracional.
\end{abstract}

RESUMEN: Este artículo discute parte de una investigación que tuvo como objetivo comprender la construcción de la identidad de adolescentes autores de infracciones durante su trayectoria escolar. El enfoque de este artículo trata de las dificultades que esos alumnos enfrentan para acceder y permanecer en el sistema educativo y las implicaciones en la constitución de sus identidades. La investigación se basó en el registro de los Libros de Ocurrencia Escolares (LOE), en procesos judiciales y en entrevistas con los adolescentes. El análisis se hizo a partir de núcleos de significación aprehendidos en los discursos de los adolescentes, en conjunto con el análisis documental. Los datos demostraron que la escuela es un lugar, para la mayoría de estos adolescentes, de reposición de identidad estigmatizada, lo que dificulta el acceso y la permanencia en ese ambiente. Por lo tanto, el estudio sugiere una urgente discusión en el ámbito de las políticas públicas de educación que tengan como objetivo el acceso y la permanencia de esos adolescentes en la escuela. PALABRAS CLAVE: Adolescentes; Educación; Infracción.

ABSTRACT: This article discusses part of a research that had as its aim to understand the construction of the identity of adolescents who committed infractions during their school trajectories. The focus of this article is the difficulties faced by these students to access and remain in the educational system and the implications in the constitution of their identities. The research was based on records of School Occurrences Books (LOE), court proceedings and interviews with adolescents. The analysis was made from nuclei of meaning detected in the discourses of the adolescents, together with the documentary analysis. The data showed that the school is a place, for most of these adolescents, that supports stigmatized identites, which makes it difficult to access and stay in school. Therefore, the study points to an urgent discussion in the scope of the public policies of education that aim at the access and permanence of these adolescents at school.

KEYWORDS: Teenagers; Education; Infractions. 


\section{Introdução}

Qualquer discussão sobre educação deve-se pautar no entendimento de que se trata de um fenômeno próprio dos seres humanos e, portanto, parte constitutiva do processo de humanização. Segundo Meira (2003), não há subjetividade plenamente desenvolvida sem apropriação do conhecimento historicamente acumulado e, para isso, é necessária a ação educativa. A educação, portanto, é condição para que o homem se constitua como humano, humanizado e humanizador.

Embora o direito a educação já fosse algo previsto na Constituição de 1988, sua efetivação como um direito fundamental à criança e ao adolescente se deu por meio da promulgação do ECA (Lei nº 8.069, 1990) e, posteriormente, da Lei de Diretrizes e Bases [LDB] (Lei n ${ }^{\circ}$ 9394, 1996), que tornaram a educação um direito de todos e dever do estado.

Porém, há dois aspectos distintos que precisam ser discutidos quando se fala de educação escolar como direito: o primeiro é o acesso, que se dá por meio da universalização e da democratização da educação escolar previstas na LDB (Lei n. 9394); e o segundo é a permanência do aluno no sistema escolar. Se o acesso, mesmo que de forma deficiente, se universaliza, o mesmo não se pode dizer da permanência dos alunos no sistema escolar. Para Leão (2006), as desigualdades continuam a se reproduzir e a se multiplicar, o que demonstra a fragilidade da concretização desse direito. Ainda que previsto no artigo 57 do ECA, a responsabilidade do poder público de proporcionar iniciativas no sentido de atender crianças e adolescentes excluídos do ensino fundamental, o que se tem visto na prática é uma permanente resistência das escolas em aceitar esse público. E quando se trata de adolescentes autores de atos infracionais, essa resistência se torna mais acirrada. No imaginário do senso comum, muito presente na sociedade, frequentemente os adolescentes autores de atos infracionais são rotulados como "bandidos", "delinquentes", "pivetes", "marginais", entre outros (Volpi, 2002). Isso porque há um descolamento do adolescente e do ato infracional de todo o contexto social, político e econômico que os produziram, sem que se leve em consideração a multideterminação do ato e dos sujeitos que os praticam. Para Volpi (2001), ato infracional é uma construção social, produzido de forma multideterminada e complexa. Apoia-se na compreensão do delito "como resultante do modo de produção social, o que define o que é delito ou não é a superestrutura jurídica e política baseada na totalidade das relações de produção" (p. 57). É por isso que Guerra e Romera (2010) defendem a necessidade de olhar para o fenômeno em sua totalidade para que não se corra o risco de naturalizar aquilo que é construído socio-historicamente:

podemos afirmar que se analisarmos a conjuntura dos adolescentes envolvidos com delito, sem fazer necessárias mediações com as relações sociais mais amplas, seremos capturados por uma visão imediatista, na qual parece que há uma vocação natural para o crime e para a violência, e se assim pensamos, torna-se impossível ajudar esses adolescentes a construírem o caminho de volta e enfrentar as vulnerabilidades sociais e pessoais que se colocam; do ponto de vista da sociedade, parece-nos que temos que assinar um contrato de fracasso, não apenas do Estado, mas também da sociedade civil nas suas mais variadas expressões, pelo fato de perdermos uma parte de nossos jovens para a "não socialidade" sem que "nada possamos fazer”. (Guerra \& Romera, 2010, p. 17) 
É, portanto, evidente a construção social do ato infracional, bem como da identidade do adolescente que o comete. É nesse sentido que a psicologia histórico-cultural defende a análise do processo e não do produto, buscando compreender o fenômeno em sua totalidade, tendo como ponto de partida o caráter histórico e social do objeto de estudo.

Vale ressaltar que, no âmbito jurídico, é considerado infrator aquela criança e/ou adolescente que praticou crime, falta ou contravenção penal, de acordo com as leis vigentes no país (Colombo, 2001). O ECA prevê medidas socioeducativas em diferentes graus de severidade, dependendo do ato cometido, levando em consideração algumas questões fundamentais, quais sejam: (a) a capacidade do adolescente em cumprir determinada medida; (b) as circunstâncias que sucedeu o suposto ato infracional; e (c) a gravidade deste último.

As medidas socioeducativas aplicáveis a adolescentes autores de atos infracionais previstas no art. 112 do ECA são: advertência, que consiste em uma repreensão judicial; obrigação de reparar do dano, que é o ressarcimento por parte do adolescente do dano ou prejuízo econômico causado à vítima; prestação de serviços à comunidade, que é a realização de tarefas gratuitas e de interesse comunitário durante período máximo de seis meses, não ultrapassando oito horas semanais; liberdade assistida, que consiste no acompanhamento, auxílio e orientação ao adolescente por equipes multidisciplinares, por um período mínimo de seis meses, objetivando inseri-los nas diversas áreas de políticas públicas, como saúde, educação, cultura, esporte, lazer e profissionalização, com vistas à sua promoção social e a inserção no mercado de trabalho; semiliberdade, em que o adolescente é vinculado a uma unidade especializada que restringe sua liberdade parcialmente, uma vez que possibilita a realização de atividades externas e a permanecer com a família aos finais de semana; e por fim a internação, que é a medida socioeducativa mais gravosa que consiste na privação total de liberdade (Lei n. 8.069, 1990).

Ainda que esteja previsto no ECA que jovens em cumprimento de medida socioeducativa devam frequentar o ensino regular, o que se constata são adolescentes predominantemente com baixa escolaridade e evadidos do sistema escolar quando fora da internação. Diversos estudos (Arroyo, 2007; Cardoso, 2009; Craidy \& Gonçalves, 2005; Gallo \& Williams, 2005; Zanella, 2010) apontam que grande parte dos adolescentes que estão em cumprimento de medidas socioeducativas estão evadidos da escola, e os que estão frequentando são considerados "problemáticos" pelos demais membros da comunidade escolar. Segundo dados do Sistema Nacional de Atendimento Socioeducativo (SINASE), dos 9.555 adolescentes em cumprimento de medida socioeducativa de internação em 2002, mais da metade (51\%) não frequentavam a escola, e quase a totalidade (90\%) não havia completado o ensino fundamental (Secretaria Especial dos Direitos Humanos, 2006). Em 2012, em pesquisa realizada pelo Conselho Nacional da Justiça (2012), os dados se mantêm: 57\% dos entrevistados declararam que estavam evadidos da escola antes de serem internados e $87 \%$ não concluíram o ensino fundamental, sendo que um número significativo (39\%) deixou de estudar entre a $5_{-}^{\mathrm{a}}$ e $6_{-}^{\mathrm{a}}$ série.

Nesse sentido, alguns autores (Gallo \& Williams, 2008; Muller, Barboza, Oliveira, Santos, \& Paludo, 2009; Pereira, 2006) apontam para a grande dificuldade da escola em manter esses adolescentes em sala de aula, seja por questões ligadas a problemas mais amplos, de ordem social, seja por desinteresse dos alunos, que muitas vezes estão associados ao fracasso escolar e aos conflitos gerados no ambiente escolar. Portanto, a escola, que deveria ser o lugar favorável para o desenvolvimento desses adolescentes, passa a ser lugar de exclusão e seleção social. 
Apesar do esforço daqueles que executam a medida socioeducativa para reinserção e a permanência do adolescente no sistema escolar, ainda persistem a rejeição por parte da escola, que leva em consideração o histórico conflituoso desse adolescente junto à instituição, o que gera um ciclo de exclusão (Collado, 2013). Bock (2003) problematiza esse cenário ao afirmar que há uma oposição entre o discurso educativo e a prática escolar. No discurso, é inegável a questão da igualdade, porém, na prática, há desigualdade, preconceitos e discriminações. Embora tais práticas sejam passíveis de penalidade, que vão de pena de detenção de seis meses a dois anos, conforme previsto no artigo 232 do ECA, é sabido que tais denúncias muitas vezes não chegam ao judiciário e quando chegam não há punição, conforme já demonstrado pela pesquisa realizada por Silveira (2012).

Logo, ao se propor pensar sobre o adolescente autor de ato infracional e a relação que este estabelece com a escola, é necessário tomar como referência toda questão social que os constituem, o que implica na busca da compreensão da sua gênese histórico-social. Só assim se terá subsídios para incrementar as discussões e os debates no âmbito de políticas públicas educacionais que dizem respeito a adolescentes autores de atos infracionais. É sobre essa problemática que o presente trabalho irá tratar. Aqui, teremos como enfoque as dificuldades enfrentadas por esses alunos de acessar e permanecer no sistema educacional e as implicações disso na constituição das suas identidades.

\section{Material e método}

Esse estudo é parte de uma pesquisa maior, intitulada "Trajetória de Alunos Protagonistas de Violência”, realizada pelo Grupo de Estudos e Pesquisas em Educação, Participação Democrática e Direitos Humanos (GEPEPEDH), que conta com a participação de pesquisadores da Universidade Estadual Paulista "Júlio de Mesquita Filho" - Campus Rio Claro/SP e da Universidade Federal de São Carlos/SP, sendo eles da área do Direito, da Psicologia e da Pedagogia e financiada pelo CNPq (edital Universal 2013).

Na primeira etapa da pesquisa, foram pesquisadas quatro escolas públicas estaduais de duas cidades do interior do Estado de São Paulo, que apresentam altos índices de violência. Na segunda etapa, foram consultados os processos judiciais existentes nas Varas da Infância e Juventude, situadas nas duas cidades do interior de São Paulo. E por fim, na terceira etapa, foram realizadas entrevistas individuais com os adolescentes identificados nos livros de ocorrências das escolas (LOE) e nos processos judiciais que cumpriram algum tipo de medida socioeducativa.

Como procedimentos de coleta de dados, a pesquisa se utilizou de três principais fontes, quais sejam: as entrevistas semi-estruturadas com adolescentes autores de atos infracionais pertencentes às escolas participantes da pesquisa-maior, as anotações registradas nos LOE e os processos judiciais relacionados a esses mesmos alunos. De forma complementar, também foram utilizadas as anotações do diário de campo da pesquisadora, a fim de melhor caracterizar os adolescentes entrevistados.

Foram analisadas cinco entrevistas com adolescentes de duas das escolas pesquisadas, contemplando as duas cidades. As entrevistas foram realizadas somente após a aprovação da pesquisa pelo Comitê de Ética em Pesquisas com Seres Humanos, aceitação dos participantes e assinatura do Termo de Consentimento Livre e Esclarecido (TCLE) pelos responsáveis e o Termo de Assentimento Livre e Esclarecido (TALE) pelos próprios adoles- 
centes. Foram conduzidas integralmente pela pesquisadora e realizadas individualmente. Apenas um adolescente não aceitou a gravação de áudio. Nesse caso, foram registradas por escrito todas as informações fornecidas durante a entrevista.

Todos os entrevistados foram do sexo masculino, na faixa etária entre 16 e 17 anos. Na ocasião da realização das entrevistas, todos estavam evadidos da escola. A maioria deixou de estudar entre a $6^{\underline{a}}$ e a $7^{\text {a }}$ série. Com relação às medidas socioeducativas às quais foram submetidos, quatro cumpriram medida socioeducativa de privação de liberdade, além de liberdade assistida (LA), e um cumpriu LA e Prestação de Serviços a Comunidade (PSC).

De forma complementar, também foram utilizados os dados dos LOE, que possibilitaram conhecer a percepção que tais instituições possuem sobre os participantes em questão e dos processos judiciais que permitiram o conhecimento do histórico infracional desses adolescentes, bem como de parte das suas histórias de vida presentes em alguns relatórios de estudos psicossociais.

Levando em consideração que essa pesquisa se embasa na perspectiva histórico- cultural (Vigotski, 1991), que, por sua vez, possui como método o materialismo histórico dialético, que tem como pressuposto a superação da dicotomia objetividade-subjetividade. Isso envolve, portanto, uma concepção de mundo, de homem e de conhecimento, já que para se conhecer a realidade estudada deve-se compreender o que é essa realidade e o homem com a qual se relaciona, sem desconsiderar sua historicidade (Gonçalves, 2007).

Sendo assim, a análise os dados foi feita a partir de núcleos de significações, proposto por Aguiar e Ozella (2006, 2013). Essa proposta metodológica tem como base a dimensão histórico-dialética, que defende que a compreensão do fenômeno estudado só é possível quando o pesquisador se aproxima das suas determinações histórico-sociais. É nesse sentido que Aguiar, Soares e Machado (2015) apontam para a necessidade da construção de um procedimento metodológico que possibilite a apreensão para além da aparência das palavras (significado) chegando a sua dimensão concreta (sentidos).

A organização dos dados das entrevistas realizadas aconteceu em três etapas: levantamento dos pré-indicadores; aglutinação de pré-indicadores em indicadores por similaridade, complementaridade e contraposição; e articulação dos indicadores para organização dos núcleos de significação, conforme proposto por Aguiar e Ozella (2006, 2013).

O levantamento dos pré-indicadores, ou seja, palavras, frases ou expressões que dessem indício daquilo que se propôs a estudar, foi realizado tendo como base os objetivos específicos da pesquisa, quais sejam: (a) Compreender de que forma a escola produziu/ produz mudanças na constituição da identidade do adolescente autor de ato infracional; (b) Identificar se os sentidos atribuídos pelos adolescentes ao ato infracional estão relacionados às atividades ligadas à sua trajetória escolar; (c) Conhecer quais as implicações que o ato infracional traz na constituição da identidade e na trajetória escolar dos adolescentes. Foram feitas várias leituras com intuito de extrair trechos que revelassem zonas de sentidos em relação à trajetória escolar dos adolescentes pesquisados.

A seguir, foi iniciada a construção dos indicadores por meio da aglutinação dos pré-indicadores de acordo com os critérios propostos por Aguiar e Ozella (2006, 2013), quais sejam: complementaridade, similaridade e contraposição. Isso permite apreender o movimento dialético dos pensamentos dos adolescentes no que se referem às suas trajetórias no meio infracional e na escola. A nomeação dos indicadores também teve como base os pressupostos teóricos e as categorias metodológicas: mediação, totalidade, historicidade, contradição, pensamento/linguagem e sentido/significado. 
Por fim foi feita a articulação dos indicadores a fim de organizá-los em núcleos de significações. Nessa etapa, foi possível identificar as transformações e contradições do processo de formação dos significados e sentidos da trajetória escolar, bem como da trajetória no meio infracional dos adolescentes entrevistados. Vale ressaltar que os núcleos foram formados levando em consideração as trajetórias escolares desses adolescentes e a construção da identidade nesse processo, que é o foco de estudo dessa pesquisa. Portanto, as vivências aqui retratadas representam "retratos" da produção identitária dos adolescentes autores de atos infracionais durante suas trajetórias escolares.

\title{
Resultados e discussão
}

A partir das análises realizadas, foi possível verificar que todos os adolescentes tiveram suas identidades marcadas pelo fracasso escolar. Ainda que dois deles trouxessem aspectos positivos da escola, todos mencionaram dificuldades relacionadas ao processo de ensino-aprendizagem e/ou ao comportamento tido como inadequado. Portanto, foi constatado que a apropriação da identidade de "aluno problema" é algo predominante entre os adolescentes entrevistados:

\begin{abstract}
Ah... nunca consegui aprender as coisas né? Sempre fui muito difícil para aprender as coisas... Aipor isso que eu bagunçava mesmo. Tenho dificuldade até hoje para aprender as coisas. Matemática essas coisas... sou meio perdido ainda né? Por causa disso aí mesmo. Acho que tem que ter força de vontade para aprender mais. Porque eu desisto das coisas rápido. Desisto das coisas rápido... as vezes o problema pode ser eu... os professores já sabem o que fazer né? Se querer [sic] aprende né? Se querer aprende. (Entrevistado 1, [grifo nosso])
\end{abstract}

sempre tive bastante dificuldade em leitura, a ler essas coisas eu sempre tive bastante [dificuldade]. Eu não gostava muito de ler assim, quando a professora me mandava ler por fileira, sabe? Eu não gostava. Eu me esforçava, lia às vezes, nem sempre. (Entrevistado 4, [grifo nosso])

[Você já abandonou a escola?] Duas vezes. Fui expulso as duas vezes. Primeira vez foi na $5^{\underline{a}}$ série e a outra na $6^{\underline{a}}$ série. [O que você mudaria na escola?] Comportamento meu. [E na escola o que precisaria mudar?] Tudo. Tudo? O que? A forma que falava com a professora, diretora, só. (Entrevistado 2, [grifo nosso])

Parece haver uma normatização, por parte da escola, das identidades destes adolescentes, sempre visando à manutenção do lugar dos excluídos, sendo eles paralisados pela reposição de identidades pressupostas. Há uma constante reposição das identidades a eles atribuídas e a incorporação do discurso de culpabilização do indivíduo pelo fracasso escolar, que se concretizou ao longo das suas histórias escolares, sintetizando-se na identidade de "aluno problema". A seguir, alguns registros de ocorrência da escola dos adolescentes entrevistados: 
Não faz a lição, conversa demais e não presta atenção na aula. Não faz nada em sala, é mal educado, não obedece, afronta o professor, encoraja os alunos a fazer bagunça e sófica no celular. Não faz as atividades, fica só com o celular. [grifo nosso]

Corre pelos corredores não faz as atividades entra em outras salas, atrapalhando a aula e não respeita as normas da escola como os outros alunos, ele sai da sala sem pedir autorização, quando bem entende. Grita pelos corredores $\boldsymbol{e}$ contamina os outros alunos com seus exemplos, já que os outros desejou [sic] segui-lo. [grifo nosso]

O aluno permaneceu andando no corredor enquanto sua sala estava na educação física. Pedi várias vezes para descer e ficar na quadra com a classe. Na troca de aula pedi para que pegasse seu material para assistir as aulas; respondeu-me que não trouxe material, deixou em casa. O aluno permaneceu na sala nas duas aulas de matemática, mas não realizou nenhuma atividade, mesmo chamando-o para explicar na lousa ele se recusou a fazer a atividade. [grifo nosso]

Sobre isso, é importante dizer que a fala dos adolescentes reflete o discurso científico predominante na sociedade, que naturaliza o fracasso escolar de forma a culpabilizar os alunos pelas suas eventuais dificuldades de aprendizagem. Com isso, fica evidente que a patologização e a judicialização da pobreza tem estado muito presentes no ambiente escolar. Psicólogos, educadores e juristas tem se unido para culpabilizar o individuo por um problema que é social (Antunes 1988; Meira, 2007; Patto, 1984; Lessa \& Facci, 2009). Assim, esses mesmos atores, que deveriam ser capazes de denunciar as verdadeiras causas das desigualdades que se reproduzem/refletem na escola, acabam por acomodar e silenciar por meio de rótulos, que vão desde um diagnóstico até um processo judicial.

Ainda sobre isso, Moysés (2001) reitera as consequências da incorporação, por parte dos alunos, desse discurso: "tomadas incapazes, bloqueiam-se. E só mostram o que sabem quando confiam. Na escola não, lá não podem saber nada, por isto não mostram: pois não foi lá que lhes disseram que não sabem?” (p. 48). Tal pesquisadora acredita que uma vez incorporado os rótulos a eles impostos, a criança ou adolescente passa a ter consequências previsíveis sobre sua autoestima e sobre seu autoconceito. Isso fica demonstrado quando o adolescente (entrevistado 1) diz em seus relatos: "nunca consegui aprender as coisas"; "sou meio perdido".

Por isso, é de fundamental importância à compreensão do fracasso escolar a partir de um olhar dos processos educacionais, uma vez que a questão é de ordem estrutural e não individual. Essa compreensão, entretanto, parece só ter sido apropriada por um dos adolescentes entrevistados, o mesmo que conseguiu superar a identidade de aluno problema e ainda fazer a crítica ao sistema educacional, entendendo que o processo de ensino- aprendizagem é dialético, sendo o professor também parte dele:

Dificuldade foi só de aprender a escrever né? Lê eu sei, mas escrever... Ah... vem do passado. Prezinho... né? Num fui aprendendo nada né? Ai cheguei no J. [escola] né? Não me ensinou também nada. Não aprendi nada. Ah... mudaria... acho que mudaria tudo. Ah... mudaria os professores nê? Mudaria todo mundo se for vê né? Colocar gente mais nova né? Mais experiente para ensinar né? essas coisas... 
queria que mudasse tudo, os professores, a direção, tudo né? Colocar pessoas mais experientes, se for vê né? Que tenha experiência né? Pra tar ensinando... ensinar os menores né? Tá aprendendo melhor né? Ah... não muda né? Os professores não muda né? Não querem saber de nada né? Querem saber só do dinheiro no bolso deles só, né? Os professores, os diretores, né? O ensino lá [escola] é péssimo né? Se for vê. Não gostei não [no ensino]. É... se professor não ensinar lá tudo certo lá né? Está ensinando? Mostrar que ele é o professor né? Aí vai pra frente a escola né? Fora isso não vai não né? (Entrevistado 4, [grifo nosso ])

Apesar do esforço deste adolescente em negar a identidade de aluno problema e de adolescente infrator que lhe foram impostas, ele esbarra nos limites colocados pela escola quanto à garantia de vaga: "se estivesse no CREAS, conseguiria vaga com certeza" (Entrevistado 4). Nota-se que há uma associação da escolarização com a ideia de caridade e não como um direito garantido por lei. Isso significa dizer que um direito que está previsto no ECA e que deveria ser garantido, se torna uma condicionalidade, no caso de adolescentes em situação de extrema vulnerabilidade e risco, a estar em cumprimento de MSE, ou seja, é necessária a intervenção do serviço de proteção social a adolescentes em cumprimento de medidas socioeducativas para que lhe seja garantido um direito básico humano e constitucional.

Eis aí mais uma contradição: violação de seus direitos acontece pelo próprio Estado, a quem compete garantir a educação a crianças e adolescentes. Vale dizer que todos os adolescentes que tiveram suas trajetórias escolares analisadas nesta pesquisa estavam defasados com relação à idade-série e também evadidos no momento da entrevista. Isso mostra que o direito à educação ainda não foi concretizado em sua plenitude. Parece que o direito é garantido somente depois que o adolescente pratica um ato infracional grave, que o coloca em privação de liberdade, não o sendo um direito para todos conforme prevê o ECA. Tanto é assim, que a maioria dos adolescentes relata uma experiência escolar positiva dentro da Fundação CASA:

[Teve algum professor que marcou a sua vida escolar?] Teve, teve sim. Ah... porque ele tentava me ajudar de qualquer jeito, Professor que tentava me ajudar de qualquer jeito, né? Não foi nem na rua para senhora vê, foi na Fundação CASA. (Entrevistado 1, [grifo nosso])

Ah... lá dentro [Fundação CASA] é diferente né? A pessoa tá sentada do seu lado, explicado todas as partes. Ah... é que nem aqui né? Se a gente pedir a atenção para professora ela vai te dar uma atenção, mas lá parece ser mais em dobro né? A atenção delas... se você pediu, a sua dificuldade, ela já senta do seu lado, trabalha em cima da sua dificuldade. Sempre dando a solução pro seu problema, sempre dando o melhor para você. (Entrevistado 4, [grifo nosso])

Quando eu cai lá dentro [Fundação CASA] eu retornei à escola. Desenvolve bastante lá dentro... Ah, a escola lá dentro lá foi boa para mim. Boa mesmo, porque aprendi bastante coisa lá dentro. Esse problema mesmo na leitura eu lia bastante (Entrevistado 5, [grifo nosso]) 
Embora prevista no artigo 57 do ECA, a necessidade de propostas diferenciadas para inserção de crianças e adolescentes excluídas do ensino fundamental obrigatório, na realidade, as escolas, de posse do poder de disponibilizar ou não a vaga escolar, muitas vezes acabam por excluir estes "alunos problemas" do seu quadro de alunos. Quando a situação se agrava e a vaga é determinada judicialmente, a exclusão acontece dentro do próprio ambiente escolar. Em pesquisas já realizadas por Dubet (2003), ficou demonstrado que alunos com dificuldades são dirigidos a uma trajetória escolar mais desvalorizada, que os impedem de ter uma carreira mais honrosa. $\mathrm{O}$ autor chega a mencionar a função meritocrática da escola, que ordena, hierarquiza, classifica os indivíduos em função de seus méritos. Isso é perceptível quando a maioria dos entrevistados justificam suas entradas no meio infracional como alternativa mais favorável diante de uma trajetória escolar negativa, que por sua vez é mencionada como culpa deles próprios:

Antes era tranquilo né? Aí ... depois você já não quer estudar, abandonar a escola e é assim ... não quer saber mais escola, fica só pra rua e assim vai embora. Ah... muda né? Mexe muito com a cabeça... tem que... ah... é ... muda né? A pessoa, o jeito de ser, o jeito de agir, já muda em todas as partes. (Entrevistado 4, [grifo nosso])

Na sexta [série] eu acho. Não sai disso... comecei o abandono até não ir mais. Abandonei a escola de vez. Aí vai para o mundo mais fácil né? $O$ mundo do crime né? Pra gente trabalhar aí, né? É a unica coisa que tá tendo pra nós, né? Se for vêe... não tenho mais o que falar não (Entrevistado 3, [grifo nosso])

Antes eu só brincava, né? Eu era tranqüilo, né? Não tinha preconceito, não tinha nada, né? Ah... no começinho eu comecei tranquilo né? Mas depois deu uma desgovernada né? Eu bagunçava... Foi quando eu fui para escola... CASA escola. (Entrevistado 1, [grifo nosso])

Portanto, falar em exclusão escolar implica necessariamente em falar de inclusão, pois exclusão não significa apenas estar fora da escola, já que muitos adolescentes podem até estar no ambiente escolar, porém excluídos do processo educativo, ao ter acesso a uma educação de baixa qualidade. Vale ainda dizer que quando se fala sobre educação de qualidade não se deve atentar apenas para os conteúdos presentes no currículo e a forma como são transmitidos, mas também a forma como são tratadas as demandas de minorias, grupos não alinhados com a cultura escolar vigente (Collado, 2013), como é o caso dos adolescentes autores de atos infracionais.

É por esse motivo que Martins (2012) defende que não se deve dicotomizar inclusão/ exclusão, uma vez que sempre há uma inclusão precária permeada por processos sociais excludentes. Isso nos faz pensar sobre as várias inclusões precárias desses adolescentes em vários âmbitos da sociedade. Para o autor, os processos excludentes além de produzirem relações desiguais e de marginalização, também cumpre o papel ideológico da "inclusão" no imaginário da sociedade. Tanto é assim que a maioria dos adolescentes entrevistados não consegue fazer a crítica com relação suas inclusões precárias ao sistema educacional. 
Mais do que isso, às vezes pode haver interesse que a identidade estigmatizada seja substituída por outra mais conveniente. Ficou demonstrado, por todos os entrevistados, por exemplo, que o aluno problema é substituído pelo aluno problema infrator, o que dá subsídios à sociedade não só a tratá-lo como problema, mas também como perigoso e marginal, garantindo-os o lugar de exclusão. A escola, por sua vez, como uma das mediações sociais desses adolescentes, também reproduz e reforça essa mesmice ao negar a vaga ou excluírem do processo educativo por serem egressos da Fundação CASA. Ainda sobre isso, é importante pontuar que, embora previsto no ECA e no SINASE, a garantia de direito à educação para estes adolescentes, o que se vê na realidade são atitudes arbitrárias de gestores de escolares pautadas em preconceito e estigmas: "Ah... já ouvi muitas coisa já né? Já falaram muita coisa para mim já... Ah... teve pessoal que falou para mim voltar para onde eu tinha acabado de sair. Professora já falou isso para mim. Já escutei muitas coisas já." (Entrevistado 1, [grifo nosso])

Mesmo não sendo mais adolescente infrator, ainda é tratado como, ou seja, "o aluno problema que virou infrator" ainda sobrevive, mesmo que alguns dos adolescentes tentem fazer esta negação. A atividade transgressora se coisifica sob forma de personagem, embora tal atividade não exista mais (Ciampa, 1987). O adolescente é considerado infrator mesmo que não esteja mais envolvido no meio infracional. Daí um aspecto importante que não deve ser desconsiderado: o personagem aluno problema que é infrator, mesmo não sendo mais autor de ato infracional, oculta a possibilidade de um personagem ativo, qual seja, o adolescente que quer ressignificar sua trajetória escolar.

\section{Considerações finais}

Portanto, fica evidente durante a análise realizada nessa pesquisa que a escola acaba por ser um lugar, para maioria destes adolescentes, de reposição de identidade estigmatizada, que sintetiza na figura do aluno problema, devido à falha no processo de ensino-aprendizagem e na relação professor-aluno.

Com a ideia de neutralidade e de condições iguais de ensino para todos, muitas vezes, professores ensinam da mesma forma, sem levar em consideração a realidade de cada aluno e seu histórico de aprendizagem e desenvolvimento, ou seja, de construção do seu modo de ser e estar na escola. Certamente, também não devem ser desconsideradas as condições materiais desses professores que os impossibilitam de refletirem sobre suas práticas e construírem formas alternativas de ensinar que contemplem aqueles que estão excluídos do processo educativo.

Isso nos faz repensar e problematizar as práticas educacionais a fim de compreender o real sentido e significado do papel da escola. Para tanto, se faz necessário que educadores saibam a serviço de quem e para que estão formando os indivíduos. Nesse sentido, o educador deve ter clara a importância do seu papel no processo educativo, pois, diferente de alguns tipos de trabalho, em que a alienação do trabalhador não prejudica a qualidade do produto, neste caso poderá contribuir para a formação de um indivíduo alienado, ou, quando não, fracassado. Isso ocorre porque o processo pedagógico implica não somente na formação do educando, mas também no próprio processo de desenvolvimento do educador e na constituição de sua identidade. Por esse motivo que educador deve estabelecer uma relação consciente com seu trabalho, compreendendo seu importante papel e compromisso com a formação humana. 
Diante disso, é possível concluir que a escola e seus atores necessitam ter clara sua responsabilidade e implicações na relação com os cidadãos que propõem formar. Como um dos principais espaços de convivência social do adolescente, poderá ser, ao mesmo tempo, uma forte colaboradora para construção de uma identidade emancipadora, com possibilidade de questionamentos da realidade vivida ou para a reposição de uma identidade "estigmatizada", na qual responsabilizará o indivíduo por todo e qualquer fracasso no âmbito escolar. Isso dependerá da forma como atores, que fazem parte do processo educacional (educadores, psicólogos, gestores), constroem sua prática profissional, considerando sempre a complexidade da realidade aqui colocada.

Sendo assim, a educação deve ter o compromisso de assumir um papel fundamental no processo de construção e transformação da sociedade e não de reposição de estigmas e enquadramento à lógica imposta pelo modo de produção capitalista, como o objetivo de formar indivíduos ativos capazes de agir de modo consciente, social, universal e livre.

Para tanto, é necessário lutar contra a seletividade, a discriminação e o rebaixamento da qualidade de ensino às camadas populares, ou seja, garantir a todos uma educação que assegure o acesso a objetivações genéricas para si. Uma educação mediadora da formação humana, que leve em consideração a realidade vivida do educando no sentido de lhe proporcionar possibilidades de vir-a-ser, o que implica necessariamente a apropriação das possibilidades socialmente existentes de desenvolvimento humano.

Entretanto, é essencial compreender que o enfrentamento não pode acontecer separado das condições que os determinam. É sabido que as políticas educacionais, muitas vezes, se apropriam inadequadamente de discursos e conhecimentos teóricos transformando-os em instrumentos para manutenção da ordem social.

A forma como a política educacional está organizada, por sua vez, dificulta sobremaneira a possibilidade de espaços para reflexão crítica das práticas educacionais, a fim de construir, juntamente com os docentes, a transformação do cotidiano escolar e a inclusão desses adolescentes no processo educativo, de forma a ressignificarem suas trajetórias escolares. Para tanto, se torna imprescindível a elaboração de políticas educacionais que visem, de fato, a transformação social, sempre, logicamente, considerando a cada passo dado os limites e as possibilidades historicamente postos para realização de uma sociedade mais justa. 


\section{Referências}

Aguiar, W. M. J. \& Ozella, S. (2006). Núcleos de significação como instrumento para a apreensão da constituição dos sentidos. Psicologia Ciência e Profissão, 26(2), 222-246.

Aguiar, W. M. J. \& Ozella, S. (2013). Apreensão dos sentidos: aprimorando a proposta dos núcleos de significação. Revista Bras. Estudos em Pedag., 94(236), 299-322.

Aguiar, W. M. J., Soares, J. B., \& Machado, V. C. (2015). Núcleos de significação: uma proposta histórico-dialética de apreensão das significações. Cadernos de Pesquisa, 45 (155), 56-75. Recuperado de http://www.scielo.br/pdf/cp/v45n155/1980-5314-cp-45-155-00056.pdf

Antunes, M. A. M. (1988). A Psicologia na Educação: algumas contribuições. Caderno USP, 5, $97-112$.

Arroyo, M. G. (2007). Quando a violência infanto-juvenil indaga a pedagogia. Educação e Sociedade, 28(100), 787-807.

Bock, A. M. B. (2003). Psicologia da Educação: cumplicidade ideológica. In M. E. M. Meira \& M. Antunes (Orgs.), Psicologia Escolar: Teorias Críticas (pp. 79-103). São Paulo: Casa do Psicólogo.

Cardoso, D. (2009). Jovens em liberdade assistida e a escola: é possível essa relação?. Revista Anagrama: Revista Científica Interdisciplinar da Graduação, 3(1), 1-14.

Craidy, C. M. \& Gonçalves, L. L. (2005). Medidas socioeducativas: da repressão à educação: a experiência do Programa de Prestação de Serviços à Comunidade da Universidade Federal do Rio Grande do Sul. Porto Alegre: Editora da UFRGS.

Ciampa, A. C. (1987). A estória do Severino e a história de Severina: um ensaio de Psicologia Social. São Paulo: Brasiliense.

Collado, D. M. S. (2013). O direito à educação escolar do adolescente autor de ato infracional no municipio de Belo Horizonte/MG. Dissertação de Mestrado, Programa de Pós-graduação em Educação, Universidade Federal de Minas Gerais, Belo Horizonte, MG.

Colombo, M.(2001). A construção do delinqüente juvenil: um estudo sobre o Adolescente infrator na cidade de Marilia. Dissertação de Mestrado, Programa de Pós-graduação em Ciências Sociais, Universidade Estadual Paulista “Julio Mesquita Filho”, Marília, SP.

Dubet, F. (2003). A escola e a exclusão. Cadernos de Pesquisa, 119, 29-45.

Gallo, A. E. \& Williams, L. C. A. (2005). Adolescentes em conflito com a lei: uma revisão dos fatores de risco na conduta infracional. Psicologia: Teoria e Prática, 7(1), 81-95.

Gallo, A. E. \& Williams, L. C. A. (2008). A escola como fator de proteção à conduta infracional de adolescentes. Cadernos de Pesquisa, 38(133), 41-59.

Gonçalves, M. G. M (2007). Fundamentos metodológicos da psicologia sócio-histórica. In A. M. B. Bock, M. G. M. Gonçalves, \& O. Furtado (Orgs.), Psicologia sócio-histórica: uma perspectiva crítica em psicologia (pp. 113-128). São Paulo: Cortez.

Guerra, G. M. S. A. \& Romera, V. M. (2010). Os adolescentes em conflito com a lei: um círculo vicioso de vítimizadores e vitimizados. ETIC - Encontro de Iniciação Científica, 6(2), 1-21.

Leão, G. M. P. (2006). Experiências de desigualdade: os sentidos da escolarização elaborados por jovens pobres. Educação e Pesquisa, 32(1), 32-48.

Lei n. 8069, de 13 de janeiro de 1990. (1990). Dispõe sobre o Estatuto da Criança e do Adolescente e dá outras providências. Brasília, DF: Presidência da República.

Lei n. 9.394, de 20 de dezembro de 1996. (1996). Estabelece as diretrizes e bases da educação nacional Brasília, DF: Presidência da República.

Lessa, P. V. \& Facci, M. G. D. (2009). O psicólogo escolar e seu trabalho frente ao fracasso escolar numa perspectiva crítica. In IX Congresso Nacional de Psicologia Escolar e Educacional, Anais eletrônicos (pp. 2-16). São Paulo: ABRAPEE. 
Martins, J. S. (2012). Exclusão social e a nova desigualdade. São Paulo: Paulus.

Meira, M. E. M. (2003). Construindo uma concepção crítica de psicologia escolar: contribuições da pedagogia histórico-crítica e da psicologia sociohistórica. In M. E. M. Meira \& M. Antunes (Orgs.), Psicologia Escolar: Teorias Críticas (pp. 13-75). São Paulo: Casa do Psicólogo.

Meira, M. E. M. (2007). Psicologia histórico-cultural: fundamentos, pressupostos e articulações com a psicologia da educação. In M. E. M. Meira \& M. G. D. Facci (Orgs.), Psicologia histórico-cultural: Contribuições para o encontro entre a subjetividade e a educação (pp. 27-62). São Paulo: Casa do Psicólogo.

Moysés, M. A. A. (2001). A institucionalização invisível: crianças que não aprendem-na-escola. Campinas, SP: Mercado das Letras.

Muller, F., Barboza, P. S., Oliveira, C. C., Santos, R, R G., \& Paludo, S. S. (2009). Perspectivas de adolescentes em conflito com a lei sobre o delito, a medida de internação e as expectativas futuras. Revista Brasileira Adolescência e Conflitualidade, 1, 70-87.

Patto, M. H. S. (1984). Psicologia e Ideologia: uma introdução crítica à Psicologia Escolar. São Paulo: Queiroz.

Pereira, I. (2006). O adolescente em conflito com a lei e o direito à educação. São Paulo: USP. Secretaria Especial dos Direitos Humanos. (2006). Sistema Nacional de Atendimento Socioeducativo - SINASE. Brasília, DF: Conanda.

Silveira, A. D. (2012). Atuação do Tribunal de Justiça de São Paulo com relação ao direito de crianças e adolescentes à educação. Revista Brasileira de Educação, 17(50), 353 -368.

Vigotski, L. S. (1991). Pensamento e linguagem. São Paulo: Martins Fontes.

Volpi, M. (2001). Sem liberdade, sem direitos: a experiência de privação de liberdade na percepção dos adolescentes em conflito com a lei. São Paulo: Cortez.

Volpi, M. (2002). O adolescente e o ato infracional. São Paulo: Cortez.

Zanella, M. N. (2010). Adolescente em conflito com a lei e a escola: uma relação possível? Revista Brasileira Adolescência e Conflitualidade, 3, 4-22.

\begin{abstract}
PRISCILA CARLA CARDOSO
https://orcid.org/0000-0002-8005-5655

É mestre em Educação pela Universidade Estadual Júlio de Mesquita Filho (2017), possui graduação em Psicologia pela Universidade Estadual Paulista Júlio de Mesquita Filho (2010). Tem especialização em Psicologia Jurídica pelo Centro Universitário de Araraquara (2013). Atualmente, é psicóloga do Centro de Referência Especializado de Assistência Social (CREAS) no município de Vinhedo e doutoranda no Programa de Pós-graduação em Educação Unesp/Rio Claro/SP. Também participa do Grupo de Estudos e Pesquisas em Educação, Participação Democrática e Direitos Humanos (GEPEPDH).
\end{abstract}

Endereço: Secretaria de Assistência Social - Rua Osvaldo Cruz, no 299 Vinhedo/SP - CEP: 13.280-093.

E-mail: priscilacarlacardoso@gmail.com 


\section{DÉBORA CRISTINA FONSECA \\ http://orcid.org/0000-0001-8427-5973}

É graduada em Psicologia pela Universidade Estadual Paulista Júlio de Mesquita Filho (1995), mestrado (2000) e doutorado (2008) em Psicologia Social pela Pontifícia Universidade Católica de São Paulo (PUC/SP). Atualmente, é docente na Universidade Estadual Paulista (UNESP), Campus Rio Claro, Dep. de Educação e Docente no Programa de Pós-graduação em Educação/UNESP / Rio Claro/SP, Linha de Pesquisa "Educação: políticas, gestão e o sujeito contemporâneo”. Tem experiência na área de Psicologia e Educação (Psicologia da Educação e Psicologia Social), desenvolvendo pesquisas na interface educação, saúde, subjetividade e políticas públicas, atuando principalmente nos seguintes temas:Adolescência e Juventude; Violência, Políticas Públicas de Saúde e Educação, Participação democrática, Conselhos de Controle Social e Defesa dos Direitos de Crianças e Adolescentes.

E-mail: debora.fonseca@unesp.br

\begin{tabular}{|c|c|}
\hline Histórico & $\begin{array}{l}\text { Submissão: } 17 / 01 / 2018 \\
\text { Revisão: } 15 / 02 / 2019 \\
\text { Aceite: } 14 / 03 / 2019\end{array}$ \\
\hline Contribuição dos autores & $\begin{array}{l}\text { Concepção: D.C.F; P.C.C } \\
\text { Coleta de dados: P.C.C. } \\
\text { Análise de dados: P.C.C. } \\
\text { Elaboração do manuscrito: D.C.F; P.C.C } \\
\text { Crítico revisões de conteúdo intelectual importante: } \\
\text { D.C.F; P.C.C } \\
\text { Final aprovação do manuscrito: D.C.F; P.C.C }\end{array}$ \\
\hline Financiamento & $\begin{array}{l}\text { CNPq, Chamada: Universal 14/2013, Processo: } \\
480714 / 2013-4 \text {. }\end{array}$ \\
\hline $\begin{array}{l}\text { Consentimento de uso de } \\
\text { imagem }\end{array}$ & $\begin{array}{l}\text { Foi obtido o consentimento escrito dos participantes e/ } \\
\text { ou do detentor dos direitos autorais sobre a imagem. }\end{array}$ \\
\hline $\begin{array}{l}\text { Aprovação, ética e } \\
\text { consentimento }\end{array}$ & $\begin{array}{l}\text { O estudo foi aprovado pelas instituições pelo Comitê de } \\
\text { Ética em Pesquisa do Instituto de Biociências da Unesp- } \\
\left.\text { Rio Claro ( } \mathrm{N}^{\mathrm{o}} 26385514.0 .0000 .5465\right) \text {. }\end{array}$ \\
\hline
\end{tabular}

